УАК 316.354:355.1/.2

ББК $60.55+68.4$

DOI 10.22394/1682-2358-2018-6-115-122

M.K. Magomedov, postgraduate student of the Humanities and Social Sciences Department, Saratov Military Order of Zhukov Red Banner Institute of the National Guard of the Russian Federation

\section{ORGANIZATIONAL \\ CULTURE \\ OF A MILITARY \\ ORGANIZATION: \\ ESSENCE, COMPONENTS, SPECIFIC CHARACTERISTICS}

The trends in the development of modern military organizations at the macro and micro levels are specified. Structural elements of a military-type organization, its functional features, as well as the nature and specificity of the organizational culture of a military organization are identified. As a result of the structural-functional analysis, the military service system was disclosed as a social phenomenon. It is proved that the main specific characteristics of the organizational culture of a military organization are totality, ambivalence, sacredness, and ethnic extrapolation.

Key words and word-combinations: military service, military organization, organizational culture, sacredness, ethnic extrapolation.
М.К. Магомедов, адбюнкт кафедрь гуманитарньгх и социальньгх наук Саратовского Военного ордена Жукоља Краснознаменного института войск наииональной гвардии Российской Федераuиu (email:mk.desperado@mail.ru)

\section{ОРГАНИЗАЦИОННАЯ КУАЬТУРА ВОЕННОЙ ОРГАНИЗАЦИИ: СУЩНОСТЬ, КОМПОНЕНТЫ, СПЕЦИФИЧЕСКИЕ ХАРАКТЕРИСТИКИ}

\begin{abstract}
Аннотация. Выявляются тенденции развития современных военных организаций на макро- и микроуровнях. Анализируются структурные элементы организации военного типа, ее функциональные особенности, а также сущность и специфика организационной культуры военной организации. На основе структурно-функционального анализа раскрыта система военной службы как социальное явление. Доказано, что основными специфическими характеристиками организационной культуры военной организации являются тотальность, двойственность, сакральность, этническая экстраполяция.

Ключевые слова и словосочетания: военная служба, военная организация, организационная культура, сакральность, этническая экстраполяция.
\end{abstract}

A

ктуальность анализа организационной культуры военной организации обусловлена Авумя факторами. Во-первых, в имеющихся научных источниках отсутствует соџиомогическая интерпретация организацион- 
ной культуры военной организации. Современные ученые данную проблему рассматривают только в общем контексте (на междисциплинарном уровне), представляя общие характеристики военной культуры российского общества. Специфика проявления культуры организации военного типа по-прежнему социологами не исследована. Во-вторых, современное реформирование гражданско-военных отношений России требует исследования проблем военной организации с разцичных позиџий, включая соџиокультурные. Современное реформирование гражданско-военных отношений, смена общественного укмада военной организации, модернизация военной организации России начали осуществцяться с момента развала Советского Союза. С одной стороны, взят курс на «либерализацию» всех сфер гражданско-военного взаимодействия; с Аругой - изменились принщипы, стратегии, цели и задачи общественногосударственного устройства России. Затяжной процесс социально-экономического реформирования сопровождался потерей традиционных принципов функционирования организаций военного типа и привеА к необходимости формирования новых стратегий соџиокультурного развития практически во всех силовых институтах общества. Посленние три десятилетия можно охарактеризовать в качестве периода трансформации организационной кумьтуры военных организаций.

Аля раскрытия изменений в системе Аанной организаџионной культуры необходимо уточнить сущностные черты и современные соџиальные функции военной организации, а также специфику служебно-трудовой деятельности военнослужащих. Именно сущность и основные функщии военной организации позвоцят рассмотреть проявление ее культурных традиџий, ценностей и норм функционирования.

Служебноо-трудовая военная деятельность человека осушествляется в специально создаваемых государственных (казенных) военных организациях, решающих задачи в области обороны и военной безопасности спеџифическими (военными) методами в цемях подготовки к вооруженной защите Отечества. Военная служба выполняется в организациях особого военного типа, представменных не только в системе Вооруженных сил РФ, но и в Аругих подразделениях войск, воинских формированиях и органах, работа которых направлена на выполнение задач охраны законности и военной безопасности военными методами [1]. Современная военная организаџия в научной китературе не имеет четкого определения, что размывает возможность уточнения сущности организационной культуры военной организации. Аیя уточнения категории «военной организации» проанализируем базовые научные подходы исследоватемей к Аанной междисџиплинарной категории.

Фундаментальную основу конџепџии системного подхода исследования военной организации составили идеи А. Богданова, $\Lambda$. фон Берталанфи, К. Боумдинга, Н. Винера и У. Эшби. Аюбая организация рассматривается ими как система, состоящая из взаимосвязанных частей и элементов (подсистем), объединенных в единый устойчивый конструкт Аля цеменаправленной военнопрофессиональной деятемьности. Системные компоненты военной организации функщионируют Аля достижения главной миссии - вооруженной защиты 
страны, что является общей целью Аля всех подсистем военной организации, обладающей иерархической структурой и способностью централизованного управления отдекьными элементами [2, с. 24].

С точки зрения теории институционацьного подхода военная организация обеспечивает взаимодействие различных военных субъектов. Возникновение и развитие организащии преимущественно зависит от институщиональной среАы. В рамках Аанной концепции соџиальная военная организация представлена в виде некой определенной институциональной структуры, характеризующейся социальным порядком, вбирающей в себя определенный опыт, систему устоявшихся законов, традиций, взаимоотношений и связей, реализующей жесткие технологии управления, не признавая случайных (стихийных) управменческих социальных процессов. Военная организация - это институт госуАарства, располагающий силами и средствами (структурные организационные компоненты Вооружкенных сил РФ, Аругих войск, воинских формирований, оборонных, научно-исследовательских организационных комплексов), материально-техническим и человеческий потенџиалом Аля достижения военных и политических целей государства.

В рамках институџионального подхода военная организация представцяет собой комплекс структурных организационных компонентов как института государственного устройства, предназначенного Аця обеспечения законности, военной безопасности не только государства, но и общества в целом. Аанная цемь Аостигается путем реализации тотального подчинения отдельных микроорганизационных систем (воинских частей) общей задаче, опредемяющей выполнение внешних и внутренних соџиальных функщий. Внешняя функция заключается в вооружкенной защите страны от внешней агрессии. Внутренняя функщия направлена на обеспечение законности, защиту от антиконститущионных действий, связанных с нарушением обеспечения общественного спокойствия, неприкосновенности жизни и зАоровья населения, нормацьного труда и отдыха гражАан, нормальной деятельности государственных и общественных организаций, учреждений и преАприятий, противоправного вооруженного насиция, угрожающего государственной целостности и неприкосновенности территории Российской Федерации [3] .

В русле структурно-функционального подхода военная организация -это сощиальный комплекс (объединение военных и гражданских трудовых комлективов), выполняющих существенный объем задач по осуществлению функщий социальной направценности [4] . Специфика обеспечения военной безопасности возмагает на военную организацию рял конкретизированных социальных функций. Прогностическая функщия заключается в прогнозировании вероятных опасностей и военных угроз интересам мичности, общества и государства. Информационная функция связана со сбором объективных данных о характере и степени военных угроз. Превентивная функщия нацелена на упреждение ици устранение возможных угроз военной безопасности на начацьных этапах их возникновения и проявления. Функция пресечения военных угроз и ликвиАации военных опасностей явцяется основной задачей военной организации, располагающей необходимыми силами и среАствами Аля достижения этой 
цели. Мобилизационная функция заключается в оперативном реагировании на угрозы, путем своевременного привлечения сил и средств дия устранения возникшей опасности [3] .

Через призму различных подходов военная организация определяется как некая регламентированная, структурированная и управцяемая часть государственного механизма, состоящая из взаимосвязанных организационных элементов (организационных воинских частей и иных социальных структур). Она действует Аля обеспечения законности, порядка, военной безопасности государства и общества. В рамках военной организации осуществляется военная служба как виА профессиональной деятельности. Военная служба попрежнему является сложным соџиальным явлением и особым видом государственной служебно-трудовой деятельности, регулируемым в рамках военных организаций на основании федеральных законов и правительственных постановлений.

Военную организацию можно ранжировать по нескольким параметрам. По форме организации - это минейно-функциональная, цемевая. По происхождению - первичная и искусственная. С точки зрения внутренних взаимоотношений она имеет специфические характеристики организационной культуры. Военная организационная культура явмяется системным элементом культуры общества и внешне выражается в стиле поведения воинского комектива, его базовых организационно культурных ценностях, принџипах, правилах и нормах служебно-трудовой деятельности. Устойчивость и цемостность военной организации обеспечивается в результате формирования особого типа военной организационной культуры (военно-организационных ценностей, принципов, правиц, норм служебно-трудовой деятельности военнослужащих). Организационная культура военной организации включает в себя нормы этикета, стиць одежды, коммуникации и практики взаимоотношений межАу военнослужащими разного ранга и воинского Аолжностного положения, субординации, воинского приветствия, составцяя неповторимый соџиокультурный менталитет [5]. Каждый военнослужащий и подразделение разАичного уровня в рамках структуры военной организации подчиняются определенным правилам и нормам, составцяющим базовую часть организационной культуры военной организации [6].

Основными специфическими характеристиками организационной культуры военной организации явцяются следующие:

1. Маскулинность - мужская прерогатива служебно-трудовой Аеятельности военнослужащих. Военнослужащий всегда считался сильным, волевым человеком иидерского типа. Военная идентичность явцяется среАством Аостижения мужского стиля поведения на основе определенных архетипов, а также устоявшихся военных ценностей, норм, принципов, традиций [7, c. 214].

2. Тотальность - характеризующаяся всеобщими идеологическими принџипами относительная соџиальная и профессионально-трудовая изоляџия, искусственно суженный круг соџиального общения, существенное ограничение свободы действий, как военнослужащего, так и членов его семьи 
[8, с. 87], Аоминирование воинских џенностей, принџипов, правиц, норм наА Аругими, высокий уровень принуждения и контромя профессиональной Аеятельности [9, с. 240]. Тотальный институт (организация) характеризуется как "место пребывания и деятельности большого количества индивиАов, которые в течение достаточно долгого времени отрезаны от внешнего мира и ведут совместно затворническую жизнь, формы которой экспиицитны и тщательно регламентированы» [10, р. 42]. Э. Гофман отмечает, что в таких военных организациях деятельность осуществляется в конкретно определенном месте, под руководством и воздействием властной структуры, носит комлективный и регламентированный характер, преследуя четкую организационную цель [10, р. 17]. Аля подобных организаций характерна специфическая среда, в которой в равной мере имеются формальные и неформальные правила регулирования отношений внутри военной организации. Аисщиплинарная практика также носит формальный и неформальный характер. По мнению М. Фуко, в рамках применения дисџиплинарной власти наказание не направлено на репрессию, а является лакмусом в действиях, поведении военнослужащего. ААминистративный контроль соотносится с набором различных установменных правиц, которым необходимо следовать. Степень соответствия или несоответствия этим правилам отмичает военнослужащих Аруг от Аруга, располагает их в определенном иерархическом порядке, устанавливает ценностную шкалу степени соответствия и устремляет к ее достижению [11, с. 267].

3. Авойственность офиџиальных и неофиџиальных ценностей, принџипов, правиц и норм культуры поведения. Тотальная система отличается намичием сложных, а порой и жестоких ритуалов; моральным и физическим принуждением, искореняющим имеющиеся ожидания и привычки, а также подчинением правилам устава организаџии. Индивид, попадая в учреждение такого типа, сталкивается с изоляцией от внешнего мира, утерей мичностной автономии и идентичности, ограничением в пространстве и времени. Возникает двойственность поведения: с одной стороны, военный актор безоговорочно подчиняется приказам и распоряжениям, отданным представитемями администраџии, стоящими выше в иерархической структуре (последнее становится необходимым условием успешной деятельности),с Аругой - демонстрирует свободный и независимый стиль поведения, некоторое игнорирование жестких норм поведения. Реализуется потребность социально-психологической разрядки, формирования относительно независимого стиля поведения, свободного от жестких и тотальных рамок повсеАневности военной организаџии.

4. Сакральная форма служебно-трудовой деятельности - формирование способности к самопожертвованию, убежденности в справедливости военных действий, почетности военной службы и служения Родине, принятие

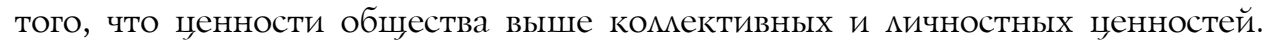
Военная служба явмяется формой организованного служения Отечеству, выполнения обязанностей по защите интересов общества и государства силовым способом. Сакральная деятельность обеспечивает преодоление ряда ог- 
раничений мичных, социально-экономических, гражданских, экономических и политических прав.

5. Экстрапомяџия этнической культуры общества на организационную культуру военной организации [12]. В настоящее время рост этнической напряженности в обществе приводит к развитию подобных противоречий в системе военных отношений. Нередко этнические ценности военнослужащих начинают преобладать наА ценностями общества и военной организацией, что приводит к повышению конфликтной напряженности, снижению патриотизма, росту этнических разногласий в воинских комлективах. В новых условиях необходимо центрацизованное противодействие стихийным проџессам, экстрапомяџия этнической культуры общества, поэтому повышается актуальность целевого управленческого формирования этнической толерантности военнослужащих, активизаџии этнической, идеологической и воспитательной работы в армии. Важна спещиализированная деятельность, направленная на этническое соџиокультурное развитие, подАержка данных процессов военной администрацией, социальными проектами, деятельностью служб соџиально-психологической работы, текстами воинской присяги, устава.

Итак, военная организация представцяет собой регламентированный, структурированный и управцяемый государственный механизм организации военной службы акторов, направленный на обеспечение законности, военной безопасности государства и общества, то есть военную социальную систему - совокупный набор организационных структур и воинских комлективов общества. ОАновременно военная организация включает в себя территориальную (набор организационных структур, военно-гражданских комлективов отдельного территориального образования) и ведомственную (набор организационных структур, военно-гражданских коммективов отдельного военного ведомственного образования) подсистемы. Первичное звено военной организации - это воинская часть (набор организационных структур, воинских, а также гражданских комлективов воинской части как микроорганизационной подсистемы общества). На разных уровнях военной организации реализуется военно-профессиональная служебно-трудовая деятельность акторов, а также разрабатываются и внедряются программы развития организащионной культуры в целом и этнической культуры военнослужащих в частности. Военную службу можно охарактеризовать как сложное соџиальное явление, преАставцяющее профессиональную Аеятельность инициированную государством в специальных военных организациях в рамках жестко мимитируемой организационной культуры для решения задач территориальной и национальной обороны с применением специфических военных методов в целях вооружкенной защиты Российской Федерации.

Организационная культура военной организации представмяет собой набор базовых ценностей, принџипов, правиц, норм, представлений, проявцяющихся в поведении военных акторов, определяющих их статус, стиль служебно-труАовой деятельности. Организационная культура военной организации явмяется не только специфическим инструментом упорядочивания жкизнедеятель- 
ности воинских комлективов, но и способом профилактики и разрешения соџиальных конфликтов в целом и этнических конфликтов военнослужащих в частности. На формирование организационной культуры военной организации вцияют разцичные общественные факторы: соџиально-экономический (развитие общественной экономики и формирование ресурсов, направцяемых на развитие культуры военных организаций); социально-политический (политическая потребность в реализации военной безопасности общества); сощиально-этнический (трансформаџия этнических отношений общества, формирование этнических конфликтов в обществе). Наиболее важным фактором обособления данной организационной культуры является общественное разделение труда, определяющее формирование противоречий в деятельности различных профессиональных групп и объединений, рост специфики требований к труду, обеспечение соџиацьной защиты субъектов труда, реализацию проектов социокуиьтурного развития. Трактовка воинского труда в контексте разновидности общественного труда с последующей дифференциацией привела к рассмотрению его в качестве относительно самостоятельной подсистемы, отражающей отдемьный компиекс автономной военной организационной культуры.

Автономизация разцичных организационных культур общества определяет трансформацию и в рамках военной субкультуры: изменение ее содержания, а также форм объективации. Постепенно усиливается тенденция перехода от агрессивных установок, форм и методов решения военных задач, радикальной направленности военной служебно-трудовой деятельности к более сглаженным и мягким формулировкам военной стратегии, становцению культурнонравственных установок, направленных на военное урегулирование, созданию условий предотвращения внешней агрессии, принуждению оппонентов к миру.

Служебно-трудовая военно-профессионацьная деятельность направлена не только на подАержание постоянной боевой готовности воинских комлективов Аля выполнения задач военной безопасности страны, но и на внешнее проявление организационной культуры военной организации. Она характеризуется экстремальными условиями служкбы, сопровождающимися риском Аля жкизни и зАоровья военнослужащих, преобладанием интересов военной службы наА мичными, ненормированным графиком трудовой деятельности, повышенной физической и психоэмоционацьной нагрузкой и ограничением мичных, социально-экономических, гражАанских, экономических и политических прав.

В рамках рассмотренных конџепций можно выделить специфические характеристики организационной культуры военной организации: маскуминность (мужская, силовая прерогатива служебно-трудовой Аеятельности военнослужащих); тотальность (всеобщность идеологических принщипов, относительная соџиальная и профессионацьно-трудовая изоляџия, искусственно суженный круг социального общения, существенное ограничение свободы действий); Авойственность поведения (размичие официальных и неформальных ценностей, принципов, правиц и норм культуры пове- 
Аения); сакральность служебно-трудовой деятельности (формирование способности к самопожертвованию, принятие ценностей общества выше комлективных и мичностных ценностей, убежденности в справедиивости военных Аействий, почетности военной службы и служения Родине); экстраполяция этнической культуры (проникновение этнической культуры общества в организационную культуру военной организации). По сути организационная культура военной организаџии представцяет собой систему тотального подчинения, состоящую из взаимосвязанных частей и элементов (подсистем), встроенных в единую культуру общества и государства. Она явмяется соџиокультурным фактором, обеспечивающим профилактику и предотвращение всякого рода нарушений, в том числе и этнических конфиктов военнослужащих.

\section{Библиографический список}

1. Фатеев К.В. Обеспечение военной безопасности Российской Федерации: теория и практика правового регулирования. М., 2005.

2. Ружанская Л.С. Теория организации. Екатеринбург, 2015.

3. Кудашкин А.B. Военная служба как вид государственной службы // Военное право. Сер: Право в Вооруженных силах - консультант. 2004. Вып. 45. С. 55-80.

4. Быченко Ю.Г., Савенко А.А. Совершенствование мотивации служебно-трудовой деятельности военнослужащих Национальной гвардии Российской Федерации // Среднерусский вестник общественных наук. 2018. Т. 13, № 3. С. 27-34.

5. Баландина Т.М., Кузнецов Н.И. Особенности социальной адаптации курсантов современного военного института // Вестник СГСЭУ. 2018. № 4 (73). С. 166-171.

6. Баландина T.M. Современные социальные технологии обновления организационной культуры // Экономические, институциональные и технологические проблемы повышения конкурентоспособности национальной экономики в условиях внешних вызовов: материалы международной научно-практической конференции. Саратов, 2015. С. $22-23$.

7. Романова Е.Н. Военная культура и ее основные характеристики / Вестник Самарского государственного университета. 2008. № 1 (60).

8. Хвостанщев C.B. Социальная адаптация семьи в условиях современного этапа социальных реформ // Вестник Поволжского института управления. 2015. № 3 (48).

9. Смелик Р.Г. Воинский труд в системе рыночных отношений. Новосибирск, 2004.

10. Goffman E. Asylums. The Essays on the Social Situation of the Mental Patients and Other Inmates. N.Y., 1961.

11. Фуко М. Надзирать и наказывать. Рождение тюрьмы. М., 1999.

12. Быченко Ю.Г., Магомедов М.К. Факторы этнического неравенства в социуме // Социальное неравенство современности: новая реальность научного осмысления: материалы VI Международной научной конференции (Саратов, 13 апреля 2018 г.). Саратов, 2018. C. 357-361. 